\title{
A adição de diferentes produtos químicos e o efeito da umidade na volatilização de amônia em cama de frango
}

\author{
Addition of chemical additives and the effect of moisture in the volatilization of ammonia in poultry \\ litter
}

\author{
Rangel Medeiros ${ }^{I}$ Bruno José Martini Santos ${ }^{\text {II }}$ Marcela Freitas ${ }^{\text {II }}$ Odete Andrade Silva ${ }^{\text {III }}$ \\ Fabrício Ferreira Alves ${ }^{\mathrm{III}}$ Elvino Ferreira ${ }^{\mathrm{IV}}$
}

\section{RESUMO}

Foi avaliada a redução da volatilização de amônia em cama de frangos por meio da adição de aditivos químicos em três experimentos. No primeiro experimento foram estudadas diferentes doses de fosfato: testemunha; 5, 10, 15, 20 e 25\%, adicionado à cama No segundo, foi estudado o efeito da umidade, para os mesmos tratamentos realizados no primeiro experimento. No terceiro experimento, foram testados diferentes aditivos na cama de frango (testemunha, Sal de Glauber, Enxofre, Sulfato de cobre, Fosfato, Sulfato de alumínio e Carbonato de sódio, nos níveis de concentração de: 1,2,3,4 e 5\%). Como resultado, obteve-se que a dose de $15 \%$ de superfosfatosimples foi a mais eficiente $(P<0,05)$, inibindo em $95 \%$ a volatilização. Pela variação no teor de umidade da cama, comprovou-se a influência inibitória da água na volatilização de amônia. Para os diferentes aditivos testados, foi constatado que o sulfato de cobre foi o melhor aditivo $(P<0,05)$ a inibir a volatilização (62\%), seguido do sulfato de alumínio (53\%) e o superfosfato simples (43\%). O uso do carbonato de sódio aumentou os níveis de volatilização de amônia (+41\%) originados da cama de frangos.

Palavras-chave: cama de frango, volatilização de amônia. aditivos.

\section{ABSTRACT}

The effect of additives to reduce volatilization of ammonia in poultry litter was evaluated in three experiments. In experiment one, different doses of phosphate, in the form of simple superphosphate, were studied by means of six treatments: 5, 10, 15, 20 and $25 \%$ added to the poultry litter. In the second experiment, the effect of humidity was verified by using the same treatments carried out in the previous experiment. In experiment three, different additives were tested in the poultry litter, following seven treatments: Glauber's salt; sulphur; copper sulphate, phosphate, aluminium sulphate; and sodium carbonate. In treatment one, the dose of $15 \%$ of simple superphosphate added to the poultry litter showed to be more effective than the other additives, for it has inhibited 95\% of the volatilization. As to experiment two, a strong inhibiting influence of water in the volatilization of ammonia could be detected. As to experiment three, the copper sulphate was the best additive $(P>0.05)$ to inhibit the poultry litter's volatilization of ammonia (62\%), followed by both the aluminium sulphate (53\%) and the simple superphosphate (43\%). The use of carbonate has promoted an increase of $41 \%$ in the levels of ammonia volatilization.

Key words: poultry litter, ammonia volatilization, additives.

\section{INTRODUÇÃO}

Na avicultura de corte, a emissão do gás amônia pode influenciar negativamente tanto o ambiente criatório como as comunidades urbanas próximas a eles (MEDEIROS, 2007). O gás amônia é incolor e irrita as mucosas (GONZÁLES \& SALDANHA, 2001) não sendo percebido pelo olfato humano em níveis menores que 20ppm (LOTT, 2003). Sua origem está na decomposição do ácido úrico presente nas excretas das aves (RANDALL et al., 2000). Níveis de 25ppm de amônia ocasionaram perdas de peso de $90 \mathrm{~g}_{\text {aves }}{ }^{-1}$ durante sete semanas de alojamento

ISetor de Epidemiologia e Saúde Pública, Prefeitura Municipal de Pinheiral, Pinheiral, RJ, Brasil.

IICurso de Medicina Veterinária, Centro Universitário de Barra Mansa (UBM), Barra Mansa, RJ, Brasil.

IIIDepartamento de Química e Bioquímica, UBM, Barra Mansa, RJ, Brasil.

${ }^{\text {IV }}$ Departamento de Nutrição Animal e Pastagens, UBM, 27330-550, Barra Mansa, RJ, Brasil. E-mail: elvinoferreira@yahoo.com.br.

Autor para correspondência 
(LOTT, 2003). Concentração superior a 60ppm predispõe doenças respiratórias, prejudicando tanto a saúde das aves como de seres humanos (KOERKAMP et al., 2000), acarretando sintomas agudos e crônicos como tosse, irritação nos olhos, fadiga, entre outros (DONHAM, 2000).

As altas concentrações de amônia são observadas na reutilização da cama de frangos (GONZÁLES \& SALDANHA, 2001). Uma das maneiras de minimizar o problema está no emprego de aditivos à cama de frangos (OLIVEIRA et al., 2003). Assim, o objetivo deste trabalho foi avaliar os aditivos químicos na volatilização de amônia oriunda da cama de frangos de corte de galpões industriais.

\section{MATERIAL E MÉTODOS}

Os experimentos foram conduzidos no Laboratório Multidisciplinar do Centro Universitário de Barra Mansa, Barra Mansa-RJ.A cama de frango utilizada foi de maravalha com quatro ciclos de 42dias com 12 aves $\mathrm{m}^{-2}$ em galpões de $1500 \mathrm{~m}^{2}$. A cada ciclo a cama era revolvida para facilitar a perda de umidade e sua compactação, sendo suas características: densidade de 0,38g cm$~^{-3}$, pH 8,3; 34,7; 8,1; 8,4 e e10, em g kg-1 , para Ca, Mg, P e K, respectivamente, Matéria orgânica 68,7\%; Carbono, 38,7\% e Nitrogênio, 3,2\%, nas frações nitrogenadas: 1010ppm para N-NH $\mathrm{NH}_{4}$ e 22,2 para N-NO .

Três experimentos foram realizados para determinar a volatilização de amônia. Diferentemente da metodologia empregada por OLIVEIRA et al. (2004), não foi adaptada uma mangueira de silicone a fim de verificar o quanto de amônia potencialmente volatilizada poderia ser fixada com a presença dos diferentes aditivos. Para o cálculo da amônia volatilizada, volatilização relativa (VR\%) e eficiência na redução da volatilização (ER\%), foram usadas as fórmulas: $\mathrm{NH}_{3}$ volatilizado $=\mathrm{N}_{\text {ác }} \mathrm{T}_{\mathrm{c}} 17 ; \mathrm{VR} \%=$ (Tratamento/ Testemunha).100 e ER\% = 100 - \%VR, em que: $N_{a ́ c}$ é a normalidade do ácido; $T_{c}$ é o título corrigido (descontado o branco) e 17 é o peso molecular da amônia.

$\mathrm{O}$ pH foi determinado usando-se $10 \mathrm{~g}$ de amostra em água deionizada $(1: 2,5)$ com agitação e repouso por uma hora e leitura em $\mathrm{pH}$-metro digital (Quimis S.A.). A matéria seca foi obtida pela diferença de peso, após estufa com ventilação forçada a $65^{\circ} \mathrm{C}$.

Empregou-se o delineamento inteiramente casualizado. A comparação das médias foi efetuada com o teste do nível mínimo de significância (LSD) a $5 \%$ de probabilidade, usando-se o pacote estatístico MSTAT-C (1998).
O experimento 1 teve como objetivo estudar a dose mais econômica de adição de fosfato, na forma de superfosfato simples (SS), em relação à redução da amônia volatilizada da cama de frango. Como indicativo dos níveis de fosfato a serem empregados, usou-se a reação da amônia (NH3) com o ácido Clorídrico concentrado $(\mathrm{HCl})$, que produz fumaça branca $\left(\mathrm{NH}_{4} \mathrm{Cl}\right)$. Não foi obtida diferença visual nas concentrações de $15 \%$ e $20 \%$ de SS, ficando estabelecido o nível de $25 \%$ como limite para esse estudo.

Três amostragens temporais seqüenciadas (coletas) foram realizadas a cada $24 \mathrm{~h}$, com três repetições por tratamento e seis níveis de aplicação do fosfato, na forma de superfosfato simples, sendo eles: testemunha, 5, 10, 15, 20 e 25\% em relação ao peso da cama de frangos de corte.

No experimento 2, o objetivo foi estudar o efeito da umidade na volatilização da amônia em cama de frango, simulando o que acontece com pequenos vazamentos nos bebedouros das aves. Assim, foi estimada que a capacidade de campo (CC) desse material em $7,74 \mathrm{~g}$ de água por grama de cama (208,51\%CC). Com a adição de $20 \mathrm{~mL}$ de água deionizada, foi alterado o nível de umidade inicial da cama obtendo-se 31,14\% da CC. Este experimento foi conduzido nos mesmos moldes do anterior.

No experimento 3, foram avaliados os tratamentos: Testemunha; Sal de Glauber $\left(\mathrm{Na}_{2} \mathrm{SO}_{4}\right)$; Enxofre; Sulfato de cobre; Fosfato; Sulfato de Alumínio e Carbonado de Sódio, com três repetições, nos níveis 1, 2, 3, 4, e 5\% em relação ao peso da cama de frangos após $24 \mathrm{~h}$.

\section{RESULTADOS E DISCUSSÃO}

No experimento 1 , foi possível verificar que à medida que aumentou as doses de fosfato (SS), foi observada a redução dos níveis de amônia volatilizada da cama de frangos, não alterandos os níveis de umidade (Tabela 1). Eficientes reduções foram obtidas em menores dosagens, em comparação com trabalhos que tiveram o mesmo objetivo, mas que usaram o gesso agrícola $\left(\mathrm{CaSO}_{4} .2 \mathrm{H}_{2} \mathrm{O}\right)$ como 42,8\% (NEME et al., 2000) e 40\% (SAMPAIO et al., 1999; OLIVEIRA et al., 2003; 2004). Contudo, para o emprego destes materiais, deve ser observada, além do custo com o frete, a diferença de preços entre os produtos.

Com a adição de $0,1 \%$ de superfosfato simples à cama de frangos criados na densidade de 12aves $\mathrm{m}^{-2}$, com três ciclos de criação, foram obtidos valores para volatilização de amônia de $7,16 \mathrm{mg} 100 \mathrm{~g}^{-1}$ $24 \mathrm{~h}^{-1}$ (OLIVEIRA et al., 2004). Níveis próximos (6,54mg $\left.100 \mathrm{~g}^{-1} 24 \mathrm{~h}^{-1}\right)$ foram obtidos com a adição de $5 \%$ de SS à cama (Tabela 1). Possivelmente a diferença em relação 
Tabela 1 - Valores médios da quantidade de amônia volatilizada, umidade e pH em cama de frangos de corte, constituída de maravalha, com quatro ciclos de criação de 42dias e densidade de 12 aves $\mathrm{m}^{-2}$ ciclo $^{-1}$, em relação aos tratamentos de adição de fosfato na forma de superfosfato simples (SS).

\begin{tabular}{|c|c|c|c|c|c|}
\hline Tratamentos & 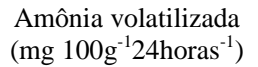 & $\begin{array}{c}\text { Volatilização relativa } \\
(\%)\end{array}$ & $\begin{array}{c}\text { Redução na volatilização } \\
(\%)\end{array}$ & Umidade (\%) & $\mathrm{pH}$ \\
\hline Testemunha & $28,6^{a}$ & 100 & - & $31,0^{a}$ & $8,4^{a}$ \\
\hline $5 \%$ SS & $6,5^{b}$ & 22,8 & 77,1 & $29,6^{\mathrm{a}}$ & $7,5^{b}$ \\
\hline $10 \% \mathrm{SS}$ & $2,3^{c}$ & 8,2 & 91,7 & $30,8^{a}$ & $7,1^{\mathrm{c}}$ \\
\hline $15 \%$ SS & $1,3^{d}$ & 4,5 & 95,4 & $26,4^{\mathrm{a}}$ & $6,7^{\mathrm{d}}$ \\
\hline $20 \%$ SS & $0,8^{d}$ & 3,0 & 96,9 & $26,3^{a}$ & $6,1^{\mathrm{e}}$ \\
\hline $25 \%$ SS & $0,8^{d}$ & 2,8 & 97,1 & $27,9^{\mathrm{a}}$ & $5,8^{f}$ \\
\hline
\end{tabular}

Médias seguidas de letras diferentes, na coluna, diferem entre si $(\mathrm{P}<0,05)$, em função do teste do nível mínimo de significância (LSD).

às dosagens e à semelhança no controle da volatilização não pode ser atribuída ao manejo daquele material, uma vez que, para ambos os casos houve, seu revolvimento para facilitar a perda de umidade. Contudo, deve ser considerado o manejo da aplicação do fosfato, que foi realizado no início de cada ciclo, como também no teor de umidade presente naquele material, uma vez que a amônia dissolve-se em água e com isso minimiza o efeito da volatilização, como verificado no experimento 2 .

Observou-se uma pequena redução $(7,19$ e $7,16 \mathrm{mg} 100 \mathrm{~g}^{-1}$ ) na volatilização de amônia quando foi diminuído o pH de 8,30 para 7,89 na comparação do tratamento testemunha em relação à adição de $0,1 \%$ superfosfato à cama de frangos, respectivamente (OLIVEIRA et al., 2004). Os efeitos da redução na volatilização de amônia estão relacionados com o decréscimo do $\mathrm{pH}$ que, com o aumento da concentração de íons $\mathrm{H}^{+}$, favorece a formação de amônio $\left(\mathrm{NH}_{4}^{+}\right)$. PROCHNOW et al. (1995), avaliando as mesmas doses de superfosfato simples praticadas no experimento 1 ( 0 a 25\%), porém em processo de compostagem em 35 dias, com partes iguais de esterco de galinha e de bovinos, obtiveram importantes efeitos na redução da volatilização. Para este caso, foi observado comportamento linear em relação ao uso do superfosfato e quadrático, quando o fosfogesso foi empregado.

Para o experimento 2, com o aumento da umidade da cama de frangos, produziu-se também um decréscimo da volatilização de amônia, o que pode ser constatado comparando-se os experimentos 1 e 2 (Tabelas 1 e 2), sem grandes mudanças nos valores de $\mathrm{pH}$. Ao serem comparados somente os tratamentos

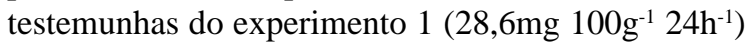


em média uma redução de 81,1\% nos níveis de amônia volatilizada. Tal fato tem por base a forte afinidade dissociativa da amônia em água. Contudo, tal tratamento não é de interesse prático, uma vez que a função básica da cama de frango é retirar a umidade nos ambientes de criação. Para tanto, pode ser adicionado aluminossilicato na ração dos animais para melhoria na consistência das fezes e redução de sua fluidez (FERREIRA et al., 2005).

Também pode ser lembrado que o elevado teor de umidade ou as condições inadequadas da cama pode promover, com os ciclos de umedecimento e

Tabela 2 - Valores médios da quantidade de amônia volatilizada em cama de frangos de corte, constituída de maravalha, com quatro ciclos de criação de 42dias e densidade de 12 aves $\mathrm{m}^{-2}$ ciclo $^{-1}$, em relação aos tratamentos de adição de fosfato na forma de superfosfato simples (SS) com umidade de $31 \%$ da capacidade de campo (CC).

\begin{tabular}{|c|c|c|c|c|}
\hline Tratamentos & 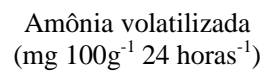 & Volatilização relativa (\%) & $\begin{array}{c}\text { Efeitos de redução na volatilização } \\
(\%)\end{array}$ & $\mathrm{pH}$ \\
\hline Testemunha & $5,4^{\text {a }}$ & 100 & - & $8,1^{\text {a }}$ \\
\hline $5 \% \mathrm{SS}$ & $2,7^{\mathrm{b}}$ & 50,1 & 49,8 & $7,4^{b}$ \\
\hline $10 \% \mathrm{SS}$ & $1,0^{\mathrm{c}}$ & 19,7 & 80,2 & $7,2^{b}$ \\
\hline $15 \% \mathrm{SS}$ & $0,4^{\text {cd }}$ & 8,7 & 91,2 & $6,8^{c}$ \\
\hline $20 \%$ SS & $0,3^{\mathrm{d}}$ & 5,6 & 94,3 & $6,4^{\mathrm{d}}$ \\
\hline $25 \%$ SS & $0,2^{d}$ & 4,7 & 95,3 & $6,2^{d}$ \\
\hline
\end{tabular}

Médias seguidas de letras diferentes, na coluna, diferem entre si $(\mathrm{P}<0,05)$, em função do teste do nível mínimo de significância (LSD). 
secagem, a compactação do material, o que propicia o aparecimento de dermatite de contato ou pododermatite nas aves. Essa patologia tem sido relatada como problema econômico para avicultura industrial de frangos e perus no Reino Unido, na América do Norte, na Austrália e no Brasil, em várias granjas no Estado de Minas Gerais (SANTOS et al., 2002). Comparandose os experimentos 1 e 2 , tem-se que o efeito da maior umidade alterou o padrão de volatilização de amônia da cama de frangos, obtendo-se comportamento exponencial $\left(\mathrm{y}=63,752 \mathrm{e}^{-0,1235 x} ; \mathrm{r}^{2}=0,89, \mathrm{P}<0,05\right)$ e linear ( $\left.\mathrm{y}=4,0986-0,19177 \mathrm{x} ; \mathrm{r}^{2}=0,78, \mathrm{P}<0,05\right)$, respectivamente (Figura 1).

Com diferentes aditivos aplicados à cama de frangos, foram obtidos diferentes níveis de redução da volatilização de amônia, com exceção daquele em que o carbonato de sódio foi utilizado (Experimento 3 - Tabela 3). Tal comportamento pode ser explicado pela reação básica do carbonato de sódio, que promoveu a elevação do pH do material. Com o estudo de regressão (Figura 2), foram obtidos ajustamentos satisfatórios entre a adição dos diferentes aditivos e a volatilização de amônia (Tabela 3). Entre os aditivos, o Sulfato de cobre foi o mais efetivo em promover, em média, uma eficiente redução nos níveis de amônia volatilizada (62\%), seguido dos tratamentos com sulfato de alumínio
(53\%) e com fosfato (43\%), em relação ao tratamento testemunha.

O aumento da densidade (10; 14; 18 e 22 aves $\mathrm{m}^{-2}$ ), bem como o avanço da época de amostragem (24, 38 e 42dias de idade), induziram aumentos da quantidade de amônia liberada e do teor de umidade na cama (HERNANDES et al., 2002). Os autores concluíram que há a necessidade de um controle rigoroso da amônia no ar dos galpões, principalmente em densidades elevadas e no período final de criação, tendo em vista a maior liberação deste gás. Com isso, a reutilização de cama por diversos ciclos de criação pode potencializar ainda mais os efeitos indesejáveis da amônia.

A reutilização de cama de frangos com um ou dois ciclos de criação de 42 dias também com 12 aves m ${ }^{2}$ foi estudada por OLIVEIRA et al. (2003). Na ausência de aditivos, os autores obtiveram maiores níveis de amônia volatilizada na cama submetida a duas criadas $\left(838,2 \mathrm{mg} 100 \mathrm{~g}^{-1}\right.$ - pH8,0) em relação àquela com um ciclo de criação (570mg 100g ${ }^{-1}$ - pH7,7). Cabe ressaltar que a base utilizada para emprego como cama de frango foi a casca de arroz, que, em função da deposição mais recente de fezes associada possivelmente à maior atividade de organismos degradadores de uratos, proporcionou teores de amônia volatilizada muito maiores do que os observados neste trabalho.

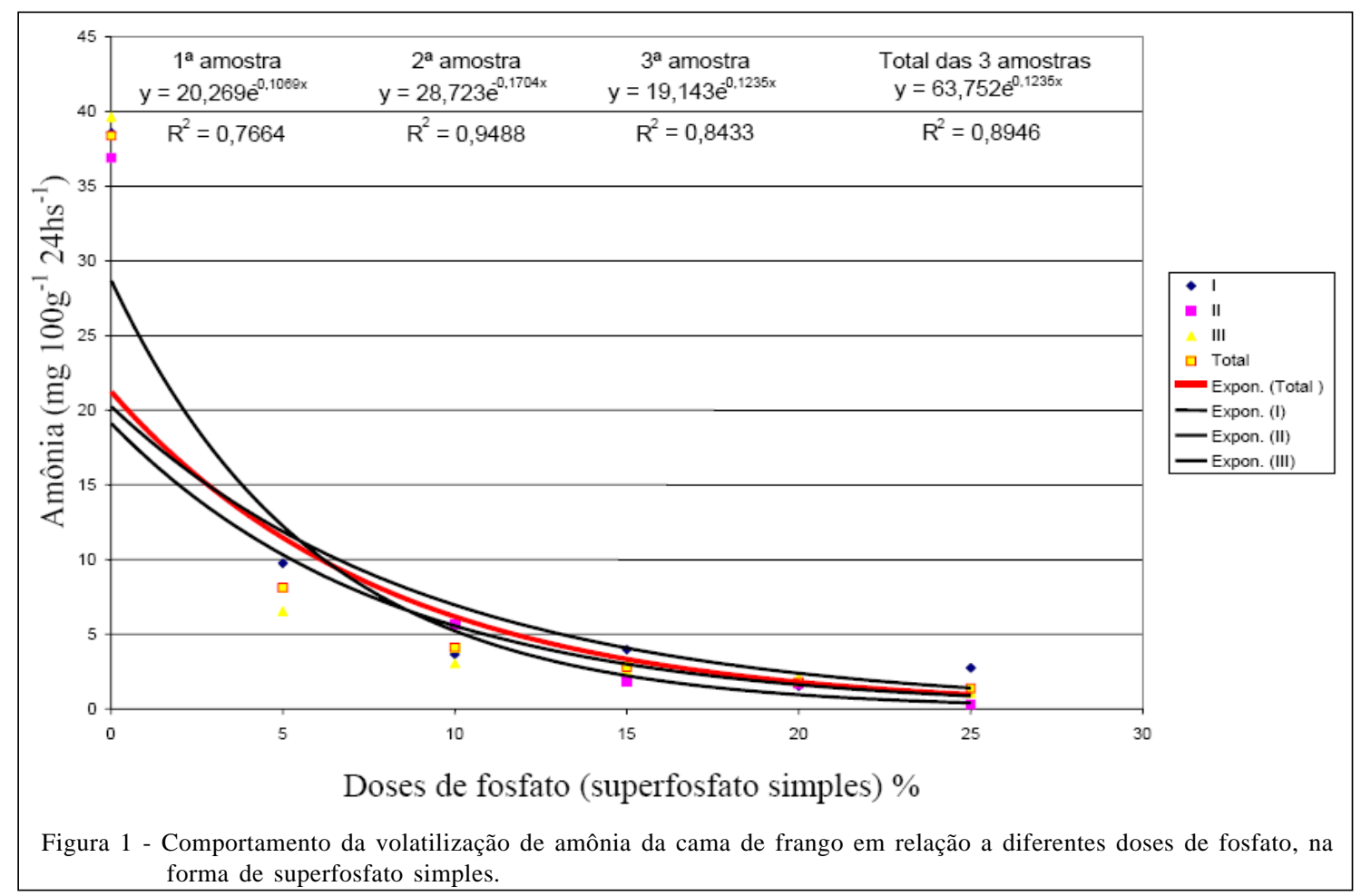

Ciência Rural, v.38, n.8, nov, 2008. 
Tabela 3 - Amônia volatilizada, volatilização relativa (VR\%), eficiência na redução (ER\%), matéria seca (MS\%), pH e equação de regressão $(\mathrm{P}<0,05)$ em cama de frangos de corte, tratadas com diferentes produtos químicos.

\begin{tabular}{|c|c|c|c|c|c|c|c|}
\hline \multicolumn{2}{|l|}{ Tratamentos } & Volatilização (mg $100 \mathrm{~g}^{-1} 24 \mathrm{~h}^{-1}$ ) & Médias & VR\% & $\mathrm{ER} \%$ & MS (\%) & $\mathrm{pH}$ \\
\hline \multicolumn{2}{|l|}{ Testemunha } & $36,7 c$ & 36,7 & 100 & - & 86.1 & 8,1 \\
\hline \multirow[t]{5}{*}{ Sal de Glauber } & $1 \%$ & 30,7 ef & & 83,7 & 16,2 & 75.8 & 7,5 \\
\hline & $2 \%$ & $27,1 \mathrm{f}$ & & 73,9 & 26,0 & 68.3 & 7,4 \\
\hline & $3 \%$ & 26,5 ef & 23,4 & 72,2 & 27,7 & 89.0 & 7,3 \\
\hline & $4 \%$ & 17,2 hi & & 46,9 & 53,0 & 58.3 & 7,2 \\
\hline & $5 \%$ & 16,7 hi & & 45,4 & 54,5 & 51.0 & 7,2 \\
\hline \multirow[t]{5}{*}{ Enxofre } & $1 \%$ & $32,3 \mathrm{~d}$ & & 88,0 & 11,9 & 50.3 & 9,9 \\
\hline & $2 \%$ & $31,8 \mathrm{~d}$ & & 86,5 & 13,4 & 50.3 & 8,0 \\
\hline & $3 \%$ & $32,8 \mathrm{~d}$ & 30,8 & 89,2 & 10,7 & 51.8 & 8,0 \\
\hline & $4 \%$ & 29,8 de & & 81,2 & 18,7 & 53.9 & 7,9 \\
\hline & $5 \%$ & 27,1 ef & & 73,8 & 26,1 & 57.4 & 7,9 \\
\hline \multirow[t]{5}{*}{ Sulfato de cobre } & $1 \%$ & $19,3 \mathrm{~h}$ & & 52,5 & 47,4 & 65.9 & 6,6 \\
\hline & $2 \%$ & $13,4 \mathrm{ij}$ & & 43,7 & 56,2 & 61.5 & 6,2 \\
\hline & $3 \%$ & $12,3 \mathrm{jk}$ & 13,4 & 33,5 & 66,4 & 66.4 & 5,9 \\
\hline & $4 \%$ & $13,2 \mathrm{ij}$ & & 35,9 & 64,0 & 69.3 & 5,6 \\
\hline & $5 \%$ & $8,6 \mathrm{kl}$ & & 23,6 & 76,3 & 62.0 & 5,3 \\
\hline \multirow[t]{5}{*}{ Fosfato } & $1 \%$ & 26,5 ef & & 72,1 & 27,8 & 63.9 & 6,9 \\
\hline & $2 \%$ & $23,5 \mathrm{fg}$ & & 64,1 & 35,8 & 66.3 & 6,8 \\
\hline & $3 \%$ & $19,8 \mathrm{gf}$ & 20,9 & 54,0 & 45,9 & 69.9 & 6,4 \\
\hline & $4 \%$ & $20,3 \mathrm{gh}$ & & 55,4 & 44,5 & 68.9 & 6,3 \\
\hline & $5 \%$ & $14,3 \mathrm{ij}$ & & 38,9 & 61,0 & 60.4 & 6,2 \\
\hline \multicolumn{2}{|c|}{ Sulfato de alumínio 1\% } & $25,1 \mathrm{f}$ & & 68,4 & 31,5 & 61.2 & 6,5 \\
\hline & $2 \%$ & $20,5 \mathrm{gh}$ & & 55,9 & 44,0 & 64.6 & 6,3 \\
\hline & $3 \%$ & $23,9 \mathrm{~h}$ & 17,2 & 65,1 & 34,9 & 67.3 & 6,1 \\
\hline & $4 \%$ & $10,7 \mathrm{jk}$ & & 29,3 & 70,7 & 60.7 & 5,8 \\
\hline & $5 \%$ & $5,9 \mathrm{l}$ & & 16,1 & 83,8 & 67.0 & 5,7 \\
\hline \multirow[t]{5}{*}{ Carbonato de sódio } & $1 \%$ & $44,4 \mathrm{c}$ & & 120,9 & $+20,9$ & 69.9 & 9,9 \\
\hline & $2 \%$ & $44,2 \mathrm{c}$ & & 120,2 & $+20,2$ & 75.0 & 10,2 \\
\hline & $3 \%$ & $53,4 \mathrm{~b}$ & $+51,7$ & 145,4 & $+45,4$ & 64.2 & 10,5 \\
\hline & $4 \%$ & 58,2 a & & 158,4 & $+58,4$ & 71.7 & 10,6 \\
\hline & $5 \%$ & 59,6 a & & 162,2 & $+62,2$ & 76.3 & 10,8 \\
\hline \multicolumn{2}{|c|}{ Aditivos } & \multicolumn{4}{|c|}{ Equação } & \multicolumn{2}{|c|}{$\mathrm{R}^{2}$} \\
\hline \multicolumn{2}{|c|}{ Sal de Glauber } & \multicolumn{4}{|c|}{$Y=35,9-4,0 X$} & \multicolumn{2}{|c|}{0,94} \\
\hline \multicolumn{2}{|l|}{ Enxofre } & \multicolumn{4}{|c|}{$Y=35,7-1,5 X$} & \multicolumn{2}{|c|}{0,83} \\
\hline \multicolumn{2}{|c|}{ Sulfato de cobre } & \multicolumn{4}{|c|}{$Y=28,7-4,5 X$} & \multicolumn{2}{|c|}{0,71} \\
\hline \multicolumn{2}{|c|}{ Superfosfato simples } & \multicolumn{4}{|c|}{$Y=33,1-3,8 X$} & \multicolumn{2}{|c|}{0,88} \\
\hline \multicolumn{2}{|c|}{ Sulfato de alumínio } & \multicolumn{4}{|c|}{$Y=34,3-5,5 X$} & \multicolumn{2}{|c|}{0,89} \\
\hline Carbonato $\mathrm{d}$ & le sódio & & $, 6+4,7 X$ & & & & \\
\hline
\end{tabular}

Médias seguidas de letras diferentes, na coluna, diferem entre si $(\mathrm{P}<0,05)$, em função do teste do nível mínimo de significância (LSD). (+) representa o acréscimo à volatilização em relação ao tratamento testemunha.

\section{CONCLUSÃO}

A dosagem de 15\% de fosfato, na forma de superfosfato simples, apresenta maior eficiência na redução da volatilização de amônia da cama de frango. A umidade presente na cama de frangos (31\% da capacidade de campo) diminuiu em $81 \%$ a quantidade de amônia volatilizada. Entre os diferentes aditivos testados, o sulfato de cobre, seguido do sulfato de alumínio e do fosfato (superfosfato simples), foram os aditivos mais eficientes em reduzir a volatilização da amônia em cama de frango.

\section{AGRADECIMENTOS}

A Reginaves Indústria e Comércio de Aves Ltda (RICA), pelo material da pesquisa, ao Conselho de Pós-graduação e Pesquisa-COPEP, pelo financiamento, aos Professores Diva Lopes da Silveira e Terry V. McIntyre, pela revisão geral deste trabalho.

Ciência Rural, v.38, n.8, nov, 2008. 


\section{REFERÊNCIAS}

DONHAM, K.J. Occupational health hazards and recommended exposure limits for workers in poultry building. In: NATIONAL POULTRY WASTE MANAGEMENT SYMPOSIUM, 2000, Auburn. Proceedings... Auburn: Auburn University, 2000. p.92-109.

FERREIRA, A.C.K. et al. O uso de aluminossolicato (Silvet ${ }^{\circledR}$ ) como adjucante na melhora do aspecto das fezes e desempenho das aves. Archives of Veterinary Science, v.10, n.1, p.117122, 2005.

GONZÁLES, E.; SALDANHA, E.S.P.B. Os primeiros dias de vida do frango e a produtividade futura. In: CONGRESSO BRASILEIRO DE ZOOTECNIA, 11., 2001, Goiânia. Anais... Goiânia: AZEG/ABZ, 2001. p.312-313.

HERNANDES, R. et al. Nitrogenous and glicydic fractions and ammonia released by broiler litter in different stocking densities and periods of breeding. Revista Brasileira de Zootecnia, v.31, n.4, p.1795-1802, 2002.

KOERKAMP, P.W.G.G. et al. Air quality management and requirements in Europe. In: NATIONAL POULTRY WASTE MANAGEMENT SYMPOSIUM, 2000, Auburn. Proceedings... Auburn: Auburn University, 2000. p.72-79.

LOTT, B. Amônia. In: Avicultura Industrial. Amônia, Grandes problemas mesmo quando você não vê. Edição 1111/ 2003. Acesso em: 12.12.2005. On line. Disponível em: http:/ / w w w. a vi c u l t u raind us tria l. com.br/site/ dinamica.asp?id=5098\&tipo_tabela=cet\&categoria=manejo.

MSTAT-C. Michigan State University - Russel D. Freed. Crop and Soil Science Departament, 1998.
NEME, R. et al. Adição de gesso agrícola em três tipos de cama de aviário na fixação de nitrogênio e no desempenho de frango de corte. Ciência Rural, Santa Maria, v.30, n.4, 2000. Acesso em: 13 maio 2008. Disponível em: http:// www.scielo.br/scielo.php?script=sci_arttext $\&$ pid $=$ S0103$84782000000400022 \& \operatorname{lng}=$ pt $\&$ nrm $=$ iso .

MEDEIROS, R. Aspergilose: risco biológico potencial para a população de Pinheiral-RJ? 2007. 44f. Monografia (Graduação em Medicina Veterinária) - Curso de Medicina Veterinária, Centro Universitário de Barra Mansa.

OLIVEIRA, M.C. et al. Efeito de condicionadores químicos sobre a qualidade da cama de frango. Arquivo Brasileiro de Medicina Veterinária e Zootecnia, v.56, n.4, p.536-541, 2004.

OLIVEIRA, M.C. et al. Teor de matéria seca, pH e amônia volatilizada da cama de frango tratada ou não com diferentes aditivos. Revista Brasileira de Zootecnia, v.32, n.4, p.951954, 2003.

PROCHNOW, L.I. et al. Controle das perdas de amônia durante a compostagem de estercos com adição de fosfogesso e superfosfato simples. Scientia Agrícola, v.52, n.2, p.346349, 1995.

RANDALL, D. et al. Equilíbrio osmótico e iônico. In:

Fisiologia animal: mecanismos e adaptações. 4.ed. Rio de Janeiro: Guanabara-Koogan, 2000. Cap.14, p.531-581.

SAMPAIO, M.A.P.M., et al. Estudo da população microbiana e da liberação de amônia da cama de frangos tratada com gesso agrícola. Arquivo Brasileiro de Medicina Veterinária e Zootecnia, v.51, n.6, p.559-564, 1999.

SANTOS, R.L. et al. Pododermatite de contato em frangos de corte. Arquivo Brasileiro de Medicina Veterinária e Zootecnia, v.54, n.6, p.655-658, 2002. 